\title{
Human Immunodeficiency Virus Type 1 Vif causes dysfunction of Cdk1 and CyclinB1: implications for cell cycle arrest
}

Keiko Sakai ${ }^{1,2+}$, R Anthony Barnitz ${ }^{1,3+}$, Benjamin Chaigne-Delalande ${ }^{1}$, Nicolas Bidère ${ }^{1,4}$ and Michael J Lenardo ${ }^{1 *}$

\begin{abstract}
The two major cytopathic factors in human immunodeficiency virus type 1 (HIV-1), the accessory proteins viral infectivity factor (Vif) and viral protein R (Vpr), inhibit cell-cycle progression at the G2 phase of the cell cycle. Although Vpr-induced blockade and the associated T-cell death have been well studied, the molecular mechanism of G2 arrest by Vif remains undefined. To elucidate how Vif induces arrest, we infected synchronized Jurkat T-cells and examined the effect of Vif on the activation of Cdk1 and CyclinB1, the chief cell-cycle factors for the G2 to M phase transition. We found that the characteristic dephosphorylation of an inhibitory phosphate on Cdk1 did not occur in infected cells expressing Vif. In addition, the nuclear translocation of Cdk1 and CyclinB1 was disregulated. Finally, Vif-induced cell cycle arrest was correlated with proviral expression of Vif. Taken together, our results suggest that Vif impairs mitotic entry by interfering with Cdk1-CyclinB1 activation.
\end{abstract}

\section{Findings}

HIV-1 infection results in cell cycle arrest at the G2 phase accompanied by massive $\mathrm{CD} 4^{+} \mathrm{T}$-cell death. Amongst the HIV-1 proteins, Vpr has been a major focus of studies for cytopathicity and G2 cell cycle arrest [1,2]. We recently showed that Vif also causes $\mathrm{CD} 4^{+} \mathrm{T}$-cell death and G2 arrest during HIV-1 infection, unveiling a connection between virus-induced cell cycle arrest and cytopathicity [3]. Whereas Vpr-induced G2 blockade has been extensively studied [4-14], how Vif causes cell cycle arrest remains poorly defined $[3,15-17]$. Here, we studied the effect of Vif expression during HIV-1 infection in vitro on important mitotic regulatory proteins.

The activation and nuclear accumulation of the Cdk1CyclinB1 kinase complex, also known as mitosis promoting factor (MPF), are key molecular events during G2/Mphase transition [18-21]. Cascades of phosphorylation and dephosphorylation govern these events at the late $\mathrm{G} 2$ phase. Once cells commit to mitotic entry, the Cdc25C phosphatase activates Cdk1 by removing two inhibitory phosphates from Thr14 and Tyr15 [22-28]. The

\footnotetext{
* Correspondence: lenardo@nih.gov

† Contributed equally

'Laboratory of Immunology, National Institutes of Allergy and Infectious

Diseases, National Institutes of Health, Bethesda, Maryland, USA

Full list of author information is available at the end of the article
}

subsequent assembly of an activated Cdk1-CyclinB1 complex initiates a positive feedback loop by phosphorylating $\mathrm{Cdc} 25 \mathrm{C}$, which increases its enzymatic activity [29]. Nuclear accumulation of MPF requires phosphorylation of CyclinB1 in the cytoplasmic retention sequence (CRS) [30-34], possibly by polo-like kinase 1 (PLK1) [35]. As a result of these events, active MPF accumulates in the nucleus and phosphorylates nuclear lamins, thereby ensuring nuclear envelope disassembly and the initiation of mitosis [36-38].

To investigate Vif-induced cell cycle arrest, we synchronized a Jurkat $\mathrm{T}$ cell line with the G1/S phase inhibitor, aphidicolin, and examined the DNA content of mock- and HIV-1-infected cells by flow cytometry [3]. Provirus expression was measured by the insertion of murine CD24 (heat stable antigen, HSA) or the enhanced green fluorescent protein (EGFP) into the Nef coding region (Figure 1A) $[3,4,7]$. Synchronized cells were released from aphidicolin after 16 hours of infection, and DNA content was monitored every 3 hours for 24 hours (Figure 1B and 1C). Cells infected with HIV-1 $1_{\mathrm{HSA}}$ e-f $+\mathrm{r}+$ (Env-negative, Vif-positive, Vpr-positive), expressing both Vif and Vpr proteins, progressed to the G2/M phase around 6 hours after release, similar to mock-infected cells (Figure 1B and 1C). Although mock-infected cells underwent mitosis and returned to G1 phase at 9 hours
C Biomed Central

(C) 2011 Sakai et al; licensee BioMed Central Ltd. This is an Open Access article distributed under the terms of the Creative Commons Attribution License (http://creativecommons.org/licenses/by/2.0), which permits unrestricted use, distribution, and reproduction in any medium, provided the original work is properly cited. 
A
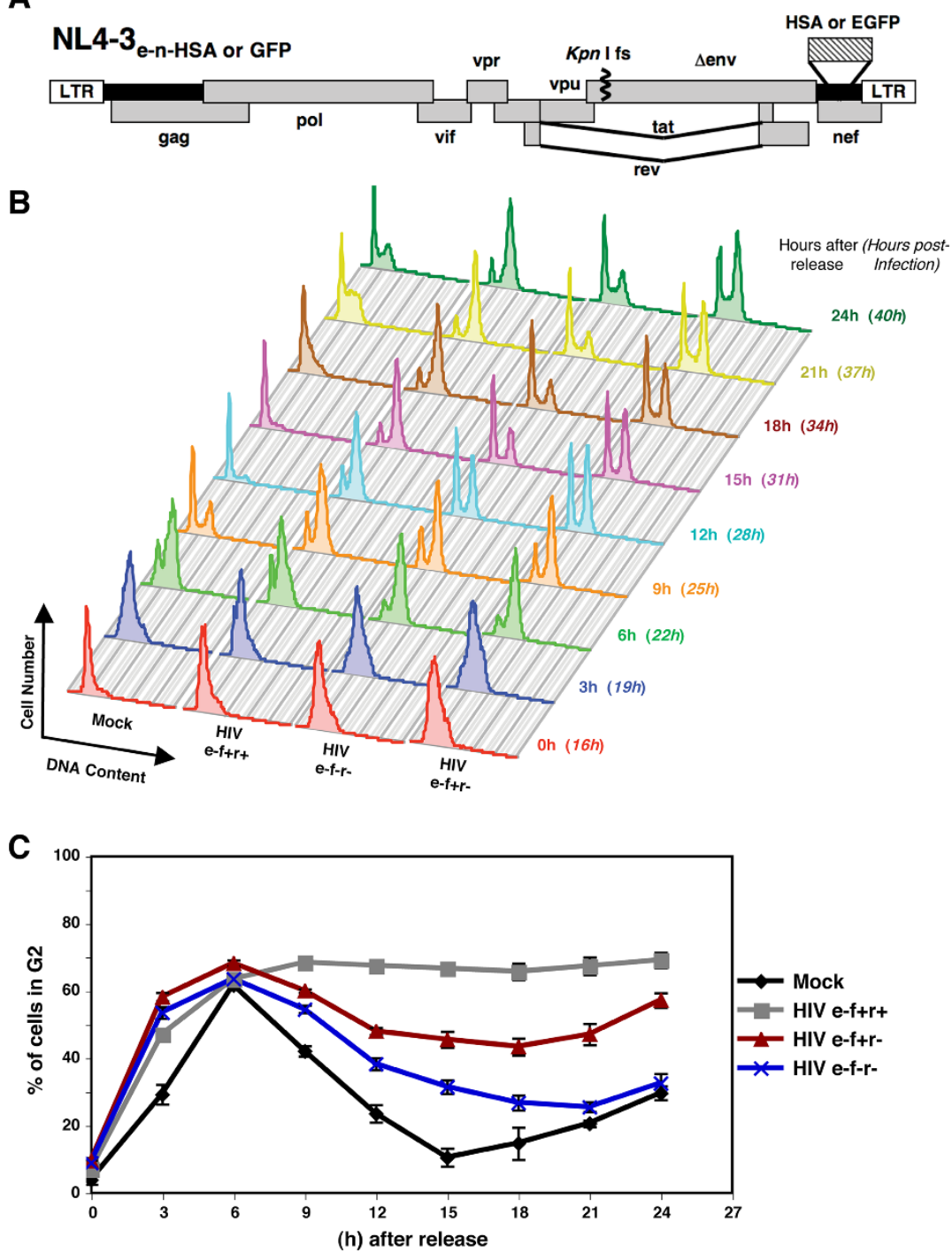

Figure 1 Vif causes prominent G2 arrest in the absence of Vpr. (A) Schematic of the NL4-3 HIV-1 molecular clones used. The NL4-3e-n-HSA

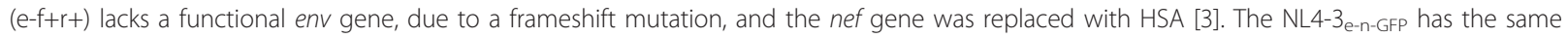
env frameshift, but the nef gene was replaced with EGFP $[4,6]$. The e-f+r- and e-f-r- mutants of NL4-3e-n-HAs and NL4-3e-n-GFP have been previously described [3,4]. (B) Jurkat cells were synchronized with a G1/S-phase blocker, aphidicolin, for 16 hours and then released for 10 hours prior to infection. The cells were blocked again at the time of infection with the following HIV-1 NL4-3e-n-HSA strains at an MOI of 5: e-f+r+, e-f+r, or e-f-r-. DNA content was examined by flow cytometry using the cell permeable dye DRAQ5 (Biostatus) every 3 hours after release from the second aphidicolin blockade as previously described [3]. Infected cells highly expressing HSA and mock-infected cells are shown. These data are representative of three experiments using either the HSA- or GFP-expressing viruses. (C) The percentage of cells in the G2 phase of the cell cycle was graphed over the course of the experiment represented in panel B. Data are represented as the mean \pm the standard deviation (SD) of quadruplicates and are representative of three experiments.

post-release, the majority of $\mathrm{Vif}+\mathrm{Vpr}+$ cells remained in G2/M phase for the duration of the experiment (24 hours) (Figure $1 \mathrm{~B}$ and $1 \mathrm{C}$ ). By comparison, the G2 arrest triggered by a e-f $+\mathrm{r}$ - virus was less dramatic than the e-f $+r+$ virus. Nevertheless, the infected cells showed striking G2 peaks that were sustained throughout the course of infection. Of note, the e-f-r- virus moderately delayed the cell cycle progression of infected cells, but failed to prevent cells from traversing back to $\mathrm{G} 1$ phase around 15-18 hours after the release (Figure 1B). These data demonstrate that Vif on its own was able to arrest cells at the G2 phase, but was less potent than cell cycle blockade by Vif and Vpr together.

To elucidate the molecular defects causing cell cycle arrest in Vif-expressing cells, we examined the translocation of MPF, which occurs at the $\mathrm{G} 2 / \mathrm{M}$ phase 
transition. Synchronized Jurkat cells were examined at 3-hour intervals post-release for the subcellular localization of Cdk1 by confocal immunofluorescence microscopy as previously described (Figure 2A and 2B)[39]. In mock-infected cells, Cdk1 was mostly cytoplasmic at 6 hours post-release. It then translocated into the nucleus at 9 hours, prior to disappearing presumably due to proteasomal degradation (Figure 2A and 2B). By contrast, Cdk1 remained essentially cytoplasmic in cells infected with either the $e-f+r+$ or the $e-f+r-$ virus (Figure $2 A a-c$ and $2 \mathrm{~B}$ ). The cells infected with the e-f-r- virus, lacking both Vif and Vpr, exhibited similar nuclear translocation of Cdk1 as the mock-infected cells, but with delayed kinetics (Figure 2Aa-c and 2B). Thus, our data suggest that Vif inhibits Cdk1 nuclear translocation whether or not $\mathrm{Vpr}$ is present.

Activation of Cdk1 is regulated by phosphorylation $[18,21]$. Inactive Cdk1 remains cytoplasmic with inhibitory phosphates attached to Thr14 and Tyr 15 until cells clear the G2 checkpoint [27,40-42]. Because of the persistent cytoplasmic localization in HIV-infected cells, we examined the phosphorylation status at Tyr 15 of Cdk1 by western blot analysis as previously described [6]. In mock-infected cells, Tyr 15 phosphorylation increased at 3 hours post-release, coinciding with the $\mathrm{S}$ to $\mathrm{G} 2$ phase transition (Figure 1B and 2B). Then, after 6 hours, the phosphorylated form, as well as the total amount of Cdk1, started to decline (Figure 2C and 2D). However, the ratio of phosphorylated to total Cdk1 continued to increase until 12 hours post-release (Figure 2D). This ratio then decreased until 18 hours post-release when both the phosphorylated form and the total amount of Cdk1 were barely detectable (Figure $2 \mathrm{C}$ and 2D). These data suggest that $\mathrm{Cdk} 1$ had become active, carried out its mitosis promoting function, and undergone degradation. Cells infected with the e-f+r+virus maintained constant Cdk1 protein levels but showed inconsistent Tyr15 phosphorylation (Figure 2C and 2D). However, Cdk1 was strongly phosphorylated and remained undegraded throughout the course of the experiment in cells infected with the $\mathrm{e}-\mathrm{f}+\mathrm{r}$ - virus (Figure $2 \mathrm{C}$ and $2 \mathrm{D}$ ). Interestingly, Tyr15 phosphorylation was more pronounced in Vif-induced G2 blockade (in the absence of Vpr). While previous studies have shown that cells expressing Vpr have more phosphorylated Cdk1 than normal cells [43-45], Vpr can also increase phosphorylation of Cdk1 at Thr14 as well as Tyr15 [43]. This may explain the discrepancy in the Tyr15 status between cells infected with the $e-f+r+$ virus versus the $e-f+r-$ virus in our experiments. Perhaps the Cdk1 in the cells infected with the e-f+r+ virus, expressing both Vpr and Vif, is still inactive due to Thr14 phosphorylation. The phosphorylation of Cdk1 Tyr15 in cells infected with the e-f-rvirus was similar to the mock-infected cells, with increased and decreased phosphorylation following the stages of the cell cycle (Figures $1 \mathrm{~B}$ and $2 \mathrm{C}$ and 2D). These data suggest that Vif can directly impede Cdk1 activation and subsequent nuclear translocation.

We also investigated the effect of HIV-1-induced cell cycle arrest on CyclinB1. Immunofluorescent staining of mock-infected cells showed that CyclinB1 translocates from the cytoplasm (6 hours post-release) to the nucleus (9 hours) (Figure 3Aa-b and 3B). Similar to Cdk1, CyclinB1 was evidently degraded and almost undetectable after 12-15 hours when cells re-entered the G1 phase (Figures 1B and 3Ac-d and 3B). This was expected since CyclinB1 is known to be degraded upon exit from mitosis [46-52]. Intriguingly, unlike Cdk1, CyclinB1 retained the ability to translocate into the nucleus by 9 hours in cells infected with either the e-f+r+ or the e-f+rvirus (Figure $3 \mathrm{Ab}$ and $3 \mathrm{~B}$ ). In addition, CyclinB1 levels persisted in infected cells throughout the course of the experiment (Figure 3A and 3B). However, after 12 hours, many HIV-infected cells that expressed Vif showed CyclinB1 had returned to the cytoplasm (Figure 3Ac-d and $3 \mathrm{~B}$ ). Cells infected with the e-f-r- virus, which do not express Vif or Vpr, exhibited similar CyclinB1 translocation and degradation as mock-infected cells, but with delayed kinetics (Figure 3A and 3B). Western blot analysis confirmed the findings from microscopy. The levels of CyclinB1 in mock-infected cells increased when cells were in G2 phase (6 hours), declined when cells were in G1 and S phases (12-18 hours), and began to increase again after 21 hours (Figures 1B and 3C). By contrast, CyclinB1 levels remained stable throughout the entire time course in HIV-1-infected cells that expressed Vif (Figure 3C). Similar to the confocal data, the levels of CyclinB1 in cells infected with the e-f-r-virus followed a similar, but delayed pattern compared to mock-infected cells (Figure 3C).

Because CyclinB1 retained the capacity to enter the nucleus in arrested cells expressing Vif, in the presence or absence of Vpr, we also examined PLK1, which phosphorylates the CyclinB1 CRS to target it to the nucleus [35]. In mock-infected cells and cells infected with the e-f-r- virus, PLK1 expression peaked around 6-9 hours, occurring before and during the nuclear accumulation of CyclinB1 as its published role would suggest. PLK1 expression then decreased at 12-18 hours, when cells progressed through mitosis (Figure 1B and 3C). Cells infected with either Vif-expressing virus exhibited an abnormal phenotype. Once PLK1 expression was induced between 3 and 12 hours, the levels remained elevated, possibly due to the G2 cell cycle arrest (Figure 3C). This increased expression of PLK1 could possibly explain the ability of CyclinB1 to still translocate into the nucleus. However, PLK1 expression remained elevated when CyclinB1 returned to the cytoplasm after 


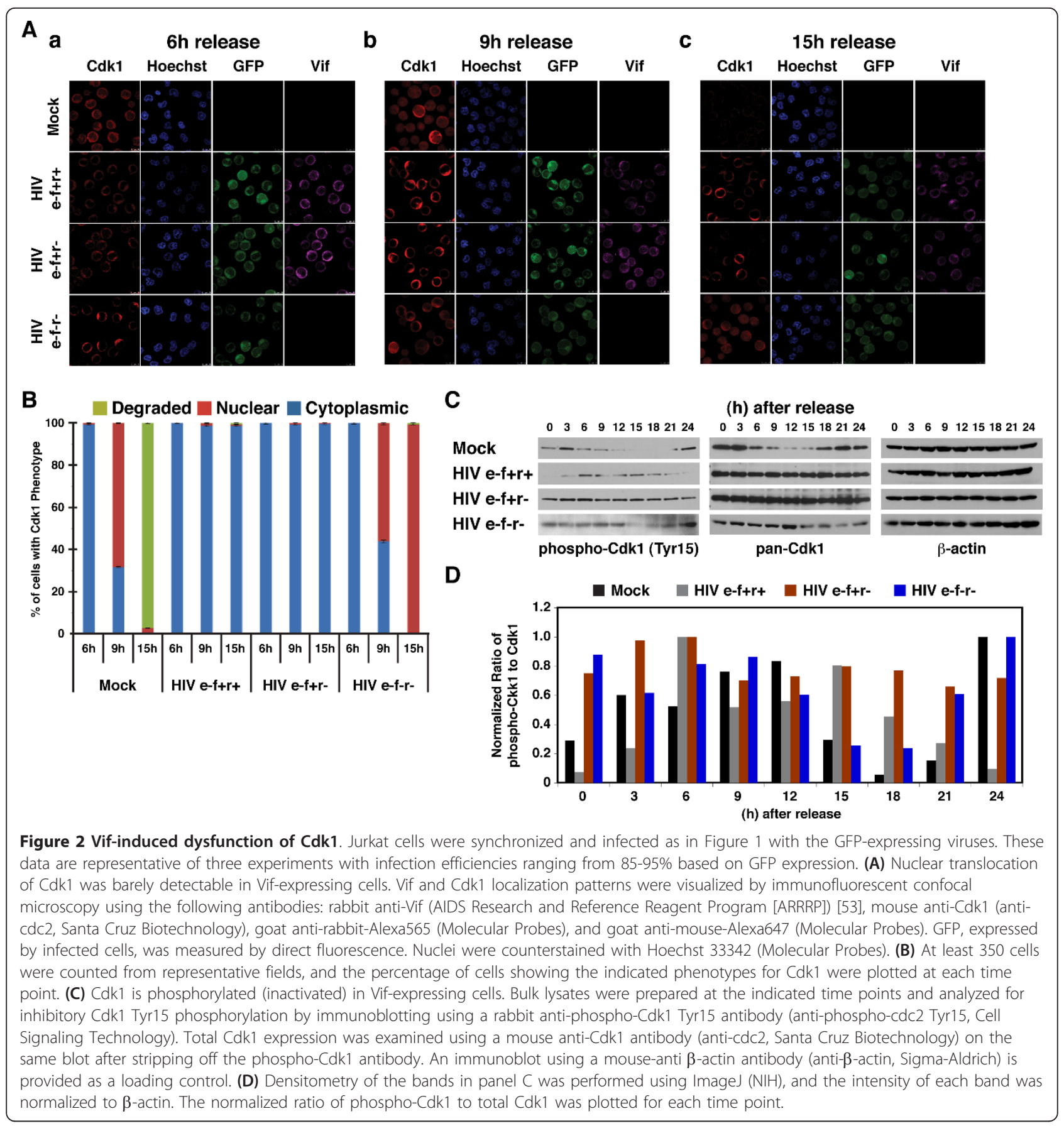

12 hours (Figure 3). This may be due to a difference in binding to the 14-3-30 scaffold protein (increased for CyclinB1 and decreased for PLK1) as we have previously shown [6].

A recent study reported that Vif induced a delay in cell cycle rather than complete arrest [15]. It is difficult to compare our results and those reported by DeHart and colleagues because the experimental system used in their study, especially the cells (SupT1 cells) and level of infection (multiplicities of infection [MOI] of 1-2), is different from ours $[3,15]$. We observed that the G2 arrest due to Vif alone was most pronounced at a high MOI. Furthermore, unlike the combination of Vpr and Vif, Vif-induced cell cycle arrest showed a direct relationship with increasing MOI (and therefore the increasing expression level of Vif), whereas the arrest caused by the $\mathrm{e}-\mathrm{f}+\mathrm{r}+$ virus appeared to be independent of MOI (Figure 4A-D). However, similar to the cell cycle 


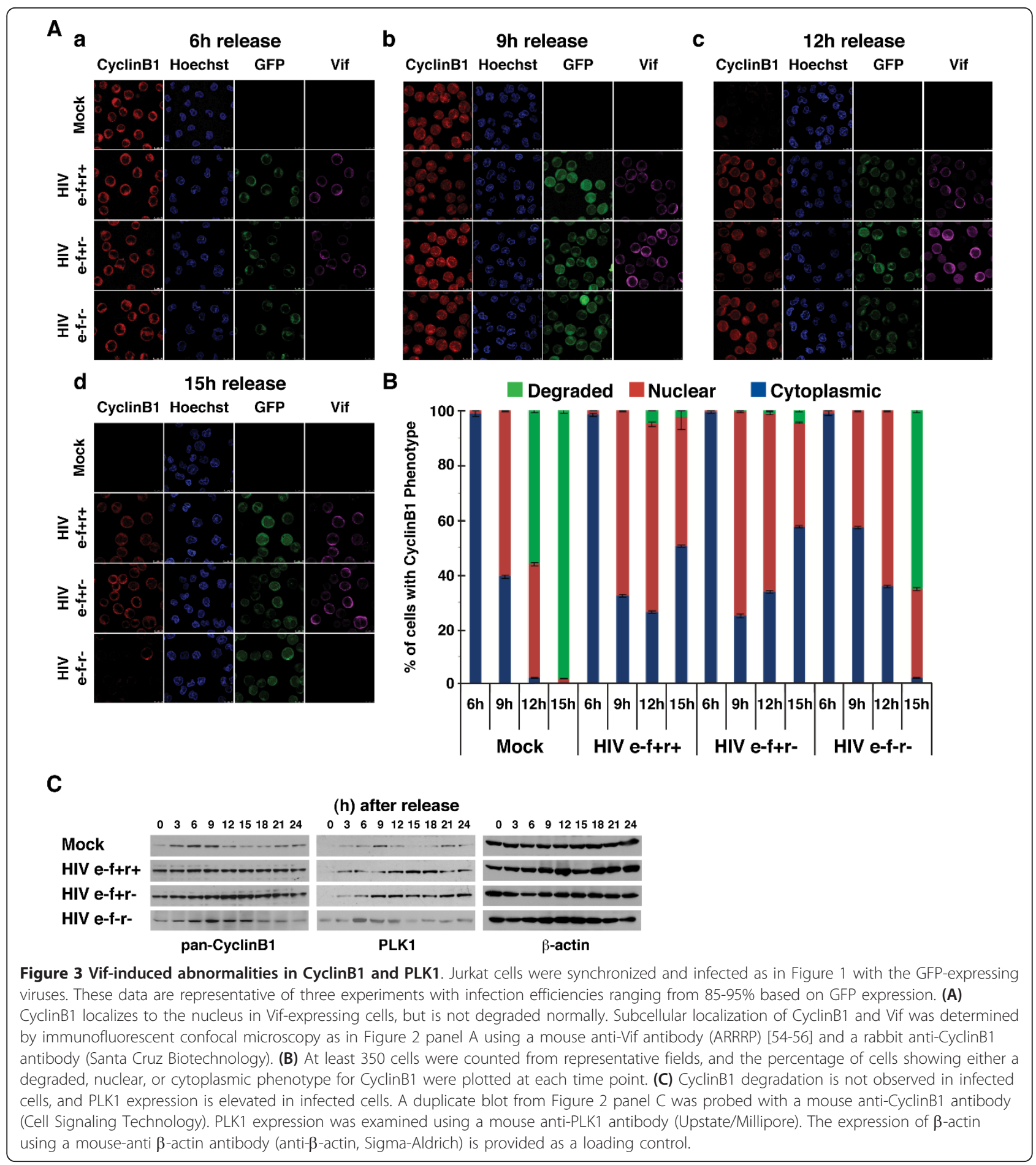

blockade caused by the e-f $+r+$ virus, cells infected with the $\mathrm{e}-\mathrm{f}+\mathrm{r}$ - virus showed the highest G2/G1 ratio on day 2 post-infection, when the expression of the provirus peaks (Figure 4 and data not shown). We observed strong cell cycle arrest caused by high levels of Vif expression in both synchronized and non-synchronized Jurkat cells (Figures 1B and 4B). As previously shown
[3], the e-f-r- virus caused no significant G2 arrest (Figure $4 \mathrm{E}$ and $4 \mathrm{~F}$ ). Thus, high expression of Vif arrested cells in the G2 phase, although not to the same degree as the combined expression of Vpr and Vif.

The HIV-1 accessory proteins Vif and Vpr block cells at the G2 phase of the cell cycle [3]. We now provide some molecular insights on how Vif induces cell cycle 
A

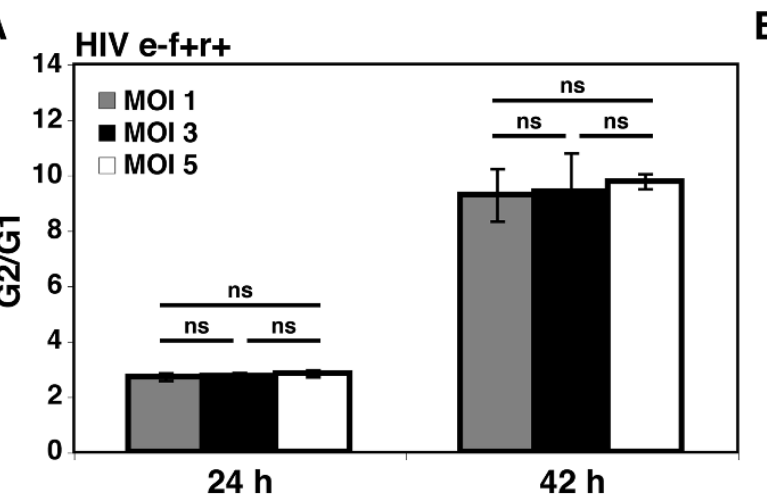

C

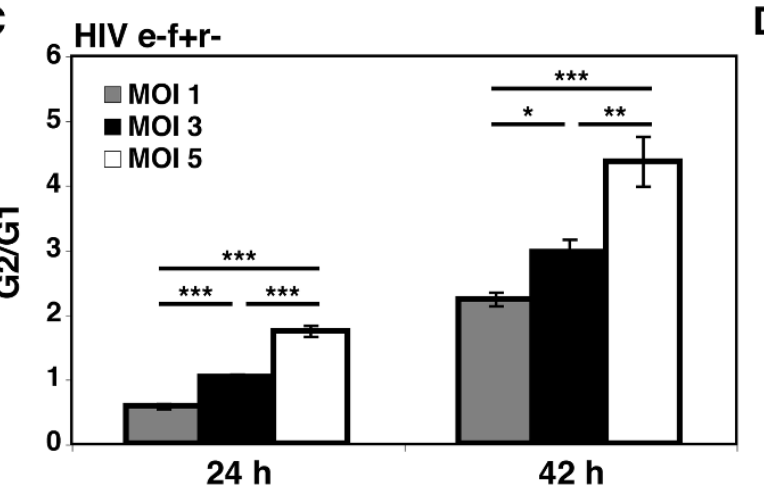

E

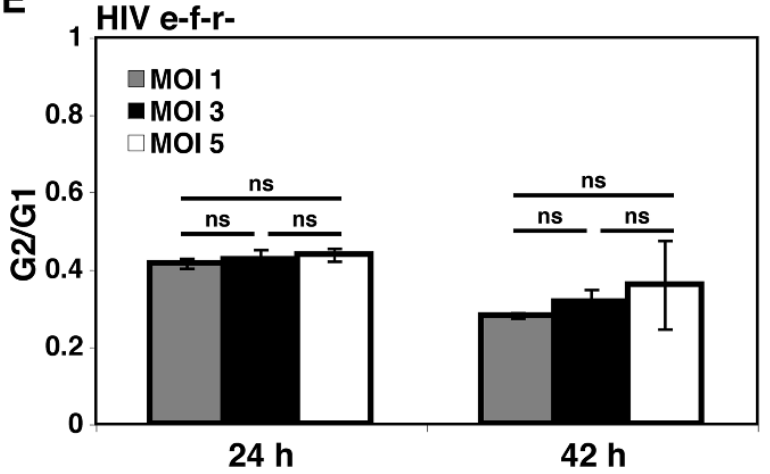

B

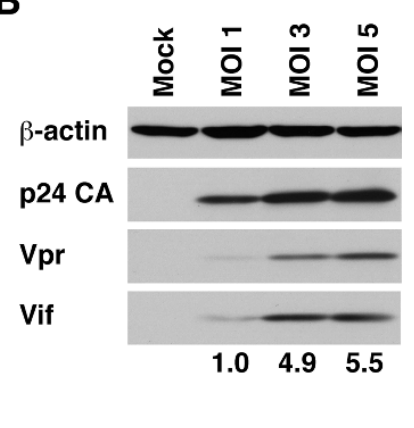

D

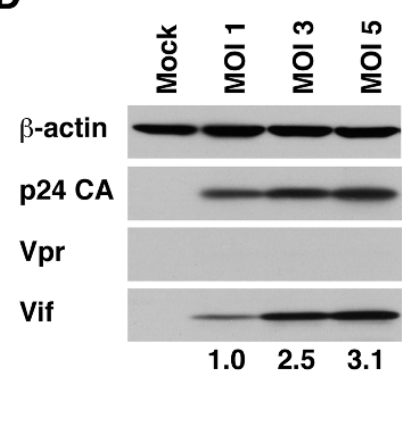

$\mathbf{F}$

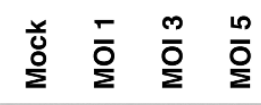

$\beta$-actin

p24 CA

$\mathrm{Vpr}$

Vif

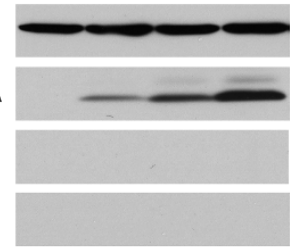

Figure 4 Vif-induced cell cycle arrest is partially dependent on MOI. Non-synchronized Jurkat cells were infected with NL4-3e-n-GFP e-f+r+ (A and B), e-f+r- (C and D), and e-f-r- (E and F) at the indicated MOls. (A, C, and E) DNA content of GFP ${ }^{+}$cells was examined by flow cytometry using DRAQ5 at 24 and 42 hours post-infection as previously described [4]. The percentage of the G2 and G1 populations were modeled using the Watson Pragmatic cell cycle model and the ratio was plotted [4]. All data were represented as mean \pm the SD of triplicates. The ns, single $\left({ }^{*}\right)$, double $(* *)$, and triple $\left(^{* *}\right)$ asterisks denote $p>0.05, p<0.05, p<0.01$, and $p<0.001$, respectively, using a one-way analysis of variance (ANOVA) with multiple-comparison tests (Prism, Graph-Pad Software). For each MOI at each time point the G2/G1 ratio for e-f $\mathrm{f}+\mathrm{r}+>\mathrm{e}-\mathrm{f}+\mathrm{r}->\mathrm{e}-\mathrm{f}-\mathrm{r}-$ with $p<0.00001$ as analyzed by a one-way ANOVA with multiple-comparison tests. (B, D, and F) The expression of Vif and Vpr increases with increasing MOls. Lysates were prepared from infected cells at 24 hours post-infection and analyzed for the expression of viral proteins by immunoblotting. The following antibodies were used: mouse anti-p24-capsid (ARRRP) [55,57], rabbit anti-Vpr (a kind gift from B. Sun), mouse anti-Vif (ARRRP) [54-56], and mouse-anti- $\beta$-actin (Sigma-Aldrich). Densitometry of the bands was performed using ImageJ (NIH), and the intensity of each band was normalized to $\beta$-actin. The fold change of Vif expression is shown under the immunoblots. These data are representative of three experiments.

arrest. Our study strongly suggests that Cdk1-CyclinB1 dysregulation accounts for Vif-mediated G2 blockade. However, the precise mechanism of this dysfunction remains to be determined. Intriguingly, cells infected with the $e-f+r+$ or the $e-f+r-$ viruses showed differences in phenotypes, especially the status of Cdk1, likely indicating different mechanisms of action for the two proteins.

Why HIV-1 has evolved two molecularly different mechanisms for G2 inhibition is an important unanswered 
question. Both forms of arrest could be byproducts of viral metabolism. Alternatively, it may be that the G2 phase is so important for a productive viral infection cycle that the virus must ensure $\mathrm{G} 2$ cell cycle arrest by two distinct mechanisms. In either case, both Vif and Vpr are major players in HIV-1 cytopathicity, and virus-induced cell cycle inhibition may be intrinsically related to viral pathogenesis. Consistent with this possibility, our previous work showed that both Vif and Vpr can independently contribute to HIV-1 cytopathicity [3]. It will be important to determine how the specific molecular pathways converge in necrotic death of arrested, infected T-cells.

\section{List of Abbreviations}

HIV-1: human immunodeficiency virus type 1; HSA: heat-stable antigen; MOI: multiplicity of infection; PLK1: polo-like kinase 1; Thr: threonine; Tyr: tyrosine; Vif: viral infectivity factor; Vpr: viral protein $\mathrm{R}$.

\section{Acknowledgements}

The following reagents were obtained through the AIDS Research and Reference Reagent Program, Division of AIDS, NIAID, NIH: HIV-1 Vif Monoclonal Antibody (\#319) from Dr. Michael H. Malim and HIV-1 ${ }_{\text {HXB2 }}$ Vif Antiserum from Dr. Dana Gabuzda. We thank Owen Schwartz for microscopy assistance; Anthony Fauci for generous availability of his BL-3 facility; Diane Bolton and the members of the Lenardo laboratory for helpful discussions. This research was supported by the Intramural Research Program of the National Institutes of Allergy and Infectious Diseases, National Institutes of Health, USA. KS was partially supported as a Research Fellow by Japan Society for the Promotion of Science (JSPS).

\section{Author details}

${ }^{1}$ Laboratory of Immunology, National Institutes of Allergy and Infectious Diseases, National Institutes of Health, Bethesda, Maryland, USA. ${ }^{2}$ Division of Viral Immunology, Center for AIDS Research, Kumamoto University, Kumamoto, Japan. ${ }^{3}$ Department of Pediatric Oncology, Dana-Farber Cancer Institute, Harvard Medical School, Boston, Massachusetts, USA. ${ }^{4}$ Institut National de la Santé et de la Recherche Médicale, Unité 542, Université ParisSud, Hôpital Paul Brousse, Villejuif, France.

\section{Authors' contributions}

$K S, R A B$, and $M J L$ designed the study. $K S, R A B, B C D$, and NB carried out the experiments. $K S, R A B, B C D, N B$, and $M J L$ interpreted data. $K S, R A B$, and $M J L$ wrote the manuscript. MJL provided financial support. All authors read and approved the final manuscript.

\section{Competing interests}

The authors declare that they have no competing interests.

Received: 18 August 2010 Accepted: 11 May 2011

Published: 11 May 2011

\section{References}

1. Andersen JL, Le Rouzic E, Planelles V: HIV-1 Vpr: mechanisms of G2 arrest and apoptosis. Exp Mol Pathol 2008, 85:2-10.

2. Dehart $J$, Planelles $V$ : Human immunodeficiency virus type $1 \mathrm{Vpr}$ links proteasomal degradation and checkpoint activation. J Virol 2008, 82:1066-1072.

3. Sakai K, Dimas J, Lenardo MJ: The Vif and Vpr accessory proteins independently cause HIV-1-induced T cell cytopathicity and cell cycle arrest. Proc Natl Acad Sci USA 2006, 103:3369-3374

4. Barnitz RA, Wan F, Tripuraneni V, Bolton DL, Lenardo MJ: Protein kinase A phosphorylation activates $\mathrm{Vpr}$-induced cell cycle arrest during human immunodeficiency virus type 1 infection. J Virol 2010, 84:6410-6424.

5. Belzile JP, Duisit G, Rougeau N, Mercier J, Finzi A, Cohen EA: HIV-1 Vprmediated G2 arrest involves the DDB1-CUL4AVPRBP E3 ubiquitin ligase. PLoS Pathog 2007, 3:e85.
6. Bolton DL, Barnitz RA, Sakai K, Lenardo MJ: 14-3-3 theta binding to cell cycle regulatory factors is enhanced by HIV-1 Vpr. Biol Direct 2008, 3:17.

7. Bolton $\mathrm{DL}$, Lenardo MJ: Vpr cytopathicity independent of G2/M cell cycle arrest in human immunodeficiency virus type 1-infected CD4+ T cells. J Virol 2007, 81:8878-8890.

8. DeHart JL, Zimmerman ES, Ardon O, Monteiro-Filho CM, Arganaraz ER, Planelles V: HIV-1 Vpr activates the G2 checkpoint through manipulation of the ubiquitin proteasome system. Virol J 2007, 4:57.

9. Hrecka K, Gierszewska M, Srivastava S, Kozaczkiewicz L, Swanson SK, Florens L, Washburn MP, Skowronski J: Lentiviral Vpr usurps Cul4-DDB1 [VprBP] E3 ubiquitin ligase to modulate cell cycle. Proc Natl Acad Sci USA 2007, 104:11778-11783.

10. Kino T, Gragerov A, Valentin A, Tsopanomihalou M, llyina-Gragerova G, Erwin-Cohen R, Chrousos GP, Pavlakis GN: Vpr protein of human immunodeficiency virus type 1 binds to 14-3-3 proteins and facilitates complex formation with Cdc25C: implications for cell cycle arrest. J Virol 2005, 79:2780-2787.

11. Le Rouzic E, Belaidouni N, Estrabaud E, Morel M, Rain JC, Transy C, Margottin-Goguet F: HIV1 Vpr arrests the cell cycle by recruiting DCAF1/ VprBP, a receptor of the Cul4-DDB1 ubiquitin ligase. Cell Cycle 2007, 6:182-188.

12. Schrofelbauer B, Hakata $Y$, Landau NR: HIV-1 Vpr function is mediated by interaction with the damage-specific DNA-binding protein DDB1. Proc Natl Acad Sci USA 2007, 104:4130-4135.

13. Tan L, Ehrlich E, Yu XF: DDB1 and Cul4A are required for human immunodeficiency virus type 1 Vpr-induced G2 arrest. J Virol 2007, 81:10822-10830

14. Wen X, Duus KM, Friedrich TD, de Noronha CM: The HIV1 protein Vpr acts to promote $\mathrm{G} 2$ cell cycle arrest by engaging a DDB1 and Cullin4Acontaining ubiquitin ligase complex using VprBP/DCAF1 as an adaptor. Biol Chem 2007, 282:27046-27057.

15. DeHart J, Bosque A, Harris RS, Planelles V: Human immunodeficiency virus type 1 Vif induces cell cycle delay via recruitment of the same E3 ubiquitin ligase complex that targets APOBEC3 proteins for degradation. J Virol 2008, 82:9265-9272.

16. Wang J, Shackelford JM, Casella CR, Shivers DK, Rapaport EL, Liu B, Yu XF, Finkel TH: The Vif accessory protein alters the cell cycle of human immunodeficiency virus type 1 infected cells. Virology 2007, 359:243-252.

17. Wang J, Shackelford JM, Selliah N, Shivers DK, O'Neill E, Garcia JV, Muthumani K, Weiner D, Yu XF, Gabuzda D, Finkel TH: The HIV-1 Vif protein mediates degradation of $\mathrm{Vpr}$ and reduces $\mathrm{Vpr}$-induced cell cycle arrest. DNA Cell Biol 2008, 27:267-277.

18. Doree M, Galas S: The cyclin-dependent protein kinases and the control of cell division. FASEB 」 1994 , 8:1114-1121.

19. Masui $Y$ : Towards understanding the control of the division cycle in animal cells. Biochem Cell Biol 1992, 70:920-945.

20. Norbury C, Nurse P: Animal cell cycles and their control. Annu Rev Biochem 1992, 61:441-470.

21. Ohi R, Gould KL: Regulating the onset of mitosis. Curr Opin Cell Biol 1999 11:267-273.

22. Dunphy WG, Kumagai $A$ : The $c d c 25$ protein contains an intrinsic phosphatase activity. Cell 1991, 67:189-196.

23. Gautier J, Solomon MJ, Booher RN, Bazan JF, Kirschner MW: cdc25 is a specific tyrosine phosphatase that directly activates p34cdc2. Cell 1991, 67:197-211.

24. Izumi T, Maller JL: Elimination of cdc2 phosphorylation sites in the cdc25 phosphatase blocks initiation of M-phase. Mol Biol Cell 1993, 4:1337-1350.

25. Lee TH, Kirschner MW: An inhibitor of $\mathrm{p} 34 \mathrm{cdc}$ /cyclin $B$ that regulates the G2/M transition in Xenopus extracts. Proc Natl Acad Sci USA 1996, 93:352-356.

26. Millar JB, Blevitt J, Gerace L, Sadhu K, Featherstone C, Russell P: p55CDC25 is a nuclear protein required for the initiation of mitosis in human cells. Proc Natl Acad Sci USA 1991, 88:10500-10504.

27. Nurse P: Universal control mechanism regulating onset of $M$-phase. Nature 1990, 344:503-508.

28. Strausfeld U, Fernandez A, Capony JP, Girard F, Lautredou N, Derancourt J, Labbe JC, Lamb NJ: Activation of p34cdc2 protein kinase by microinjection of human cdc25C into mammalian cells. Requirement for prior phosphorylation of $\mathrm{cdc} 25 \mathrm{C}$ by $\mathrm{p} 34 \mathrm{cdc} 2$ on sites phosphorylated at mitosis. J Biol Chem 1994, 269:5989-6000. 
29. Hoffmann I, Clarke PR, Marcote MJ, Karsenti E, Draetta G: Phosphorylation and activation of human cdc25-C by $\mathrm{cdc} 2-\mathrm{cyclin} \mathrm{B}$ and its involvement in the self-amplification of MPF at mitosis. EMBO J 1993, 12:53-63.

30. Hagting A, Jackman M, Simpson K, Pines J: Translocation of cyclin B1 to the nucleus at prophase requires a phosphorylation-dependent nuclear import signal. Curr Biol 1999, 9:680-689.

31. Pines J, Hunter T: Human cyclins $A$ and $B 1$ are differentially located in the cell and undergo cell cycle-dependent nuclear transport. J Cell Biol 1991, 115:1-17.

32. Pines J, Hunter $\mathrm{T}$ : The differential localization of human cyclins $A$ and $B$ is due to a cytoplasmic retention signal in cyclin B. EMBO J 1994, 13:3772-3781.

33. Yang J, Bardes ES, Moore JD, Brennan J, Powers MA, Kornbluth S: Control of cyclin B1 localization through regulated binding of the nuclear export factor CRM1. Genes Dev 1998, 12:2131-2143.

34. Yang J, Song H, Walsh S, Bardes ES, Kornbluth S: Combinatorial control of cyclin B1 nuclear trafficking through phosphorylation at multiple sites. J Biol Chem 2001, 276:3604-3609.

35. Toyoshima-Morimoto F, Taniguchi E, Shinya N, Iwamatsu A, Nishida E: Pololike kinase 1 phosphorylates cyclin B1 and targets it to the nucleus during prophase. Nature 2001, 410:215-220.

36. Chou YH, Bischoff JR, Beach D, Goldman RD: Intermediate filament reorganization during mitosis is mediated by p34cdc2 phosphorylation of vimentin. Cell 1990, 62:1063-1071.

37. Dessev G, lovcheva-Dessev C, Bischoff JR, Beach D, Goldman R: A complex containing p34cdc2 and cyclin B phosphorylates the nuclear lamin and disassembles nuclei of clam oocytes in vitro. J Cell Biol 1991, 112:523-533.

38. Peter M, Nakagawa J, Doree M, Labbe JC, Nigg EA: In vitro disassembly of the nuclear lamina and $\mathrm{M}$ phase-specific phosphorylation of lamins by cdc2 kinase. Cell 1990, 61:591-602.

39. Su H, Bidere N, Zheng L, Cubre A, Sakai K, Dale J, Salmena L, Hakem R, Straus S, Lenardo M: Requirement for caspase-8 in NF-kappaB activation by antigen receptor. Science 2005, 307:1465-1468.

40. Krek W, Nigg EA: Mutations of p34cdc2 phosphorylation sites induce premature mitotic events in HeLa cells: evidence for a double block to p34cdc2 kinase activation in vertebrates. EMBO J 1991, 10:3331-3341.

41. Krek W, Nigg EA: Differential phosphorylation of vertebrate p34cdc2 kinase at the G1/S and G2/M transitions of the cell cycle: identification of major phosphorylation sites. EMBO J 1991, 10:305-316.

42. Norbury C, Blow J, Nurse P: Regulatory phosphorylation of the p34cdc2 protein kinase in vertebrates. EMBO J 1991, 10:3321-3329.

43. He J, Choe S, Walker R, Di Marzio P, Morgan DO, Landau NR: Human immunodeficiency virus type 1 viral protein $\mathrm{R}(\mathrm{Vpr})$ arrests cells in the G2 phase of the cell cycle by inhibiting p34cdc2 activity. J Virol 1995, 69:6705-6711.

44. Jowett JB, Planelles V, Poon B, Shah NP, Chen ML, Chen IS: The human immunodeficiency virus type $1 \mathrm{vpr}$ gene arrests infected $T$ cells in the G2 + M phase of the cell cycle. J Virol 1995, 69:6304-6313.

45. Re F, Braaten D, Franke EK, Luban J: Human immunodeficiency virus type $1 \mathrm{Vpr}$ arrests the cell cycle in $\mathrm{G} 2$ by inhibiting the activation of p34cdc2-cyclin B. J Virol 1995, 69:6859-6864.

46. Gallant P, Nigg EA: Cyclin B2 undergoes cell cycle-dependent nuclear translocation and, when expressed as a non-destructible mutant, causes mitotic arrest in HeLa cells. J Cell Biol 1992, 117:213-224.

47. Ghiara JB, Richardson HE, Sugimoto K, Henze M, Lew DJ, Wittenberg C, Reed SI: A cyclin B homolog in S. cerevisiae: chronic activation of the Cdc28 protein kinase by cyclin prevents exit from mitosis. Cell 1991, 65:163-174.

48. Holloway SL, Glotzer M, King RW, Murray AW: Anaphase is initiated by proteolysis rather than by the inactivation of maturation-promoting factor. Cell 1993, 73:1393-1402.

49. Murray AW, Solomon MJ, Kirschner MW: The role of cyclin synthesis and degradation in the control of maturation promoting factor activity. Nature 1989, 339:280-286.

50. Glotzer M, Murray AW, Kirschner MW: Cyclin is degraded by the ubiquitin pathway. Nature 1991, 349:132-138.

51. Hershko A, Ganoth D, Pehrson J, Palazzo RE, Cohen LH: Methylated ubiquitin inhibits cyclin degradation in clam embryo extracts. $J$ Biol Chem 1991, 266:16376-16379.

52. Murray AW, Kirschner MW: Cyclin synthesis drives the early embryonic cell cycle. Nature 1989, 339:275-280.
53. Goncalves J, Jallepalli P, Gabuzda DH: Subcellular localization of the Vif protein of human immunodeficiency virus type 1. J Virol 1994, 68:704-712.

54. Fouchier RA, Simon JH, Jaffe AB, Malim MH: Human immunodeficiency virus type 1 Vif does not influence expression or virion incorporation of gag-, pol-, and env-encoded proteins. J Virol 1996, 70:8263-8269.

55. Simon JH, Fouchier RA, Southerling TE, Guerra CB, Grant CK, Malim MH: The Vif and Gag proteins of human immunodeficiency virus type 1 colocalize in infected human T cells. J Virol 1997, 71:5259-5267.

56. Simon JH, Southerling TE, Peterson JC, Meyer BE, Malim MH: Complementation of vif-defective human immunodeficiency virus type 1 by primate, but not nonprimate, lentivirus vif genes. J Virol 1995, 69:4166-4172.

57. Fouchier RA, Meyer BE, Simon JH, Fischer U, Malim MH: HIV-1 infection of non-dividing cells: evidence that the amino-terminal basic region of the viral matrix protein is important for Gag processing but not for postentry nuclear import. EMBO J 1997, 16:4531-4539.

doi:10.1186/1743-422X-8-219

Cite this article as: Sakai et al:: Human Immunodeficiency Virus Type 1 Vif causes dysfunction of Cdk1 and CyclinB1: implications for cell cycle arrest. Virology Journal 2011 8:219.

\section{Submit your next manuscript to BioMed Central and take full advantage of:}

- Convenient online submission

- Thorough peer review

- No space constraints or color figure charges

- Immediate publication on acceptance

- Inclusion in PubMed, CAS, Scopus and Google Scholar

- Research which is freely available for redistribution 